\title{
RESPONSABILIZAÇÃO DOS PROVEDORES DE CONTEÚDO NAS RELAÇÕES DE E-COMMERCE
}

\author{
Luma Vilela Ramos Fonseca*1 \\ Isabella Thalita Andretto Oliveira ${ }^{* 2}$
}

RESUMO: O presente estudo tem como objetivo analisar os contornos conferidos a relação estabelecida por meio do e-commerce entre o provedor de conteúdo e o comprador e, eventualmente, entre ambos e um segundo provedor, a fim de verificar qual o tratamento jurídico adequado para a sua responsabilização. Para tanto, propõe-se a responsabilização civil objetiva dos provedores de conteúdo nos moldes do Código de Defesa do Consumidor, haja vista que, apesar de ser uma relação contratual firmada por um veículo de comunicação diferente, caracteriza-se como uma relação de consumo, sobre a qual deverá recair todas as peculiaridades e prerrogativas típicas deste ramo.

Palavras-chave: E-commerce. Provedores de Conteúdo. Relação de Consumo. Responsabilidade Objetiva. Código de Defesa do Consumidor.

\section{RESPONSIBILITY OF CONTENT PROVIDERS IN E-COMMERCE RELATIONS}

ABSTRACT: The present study aims to analyze the contours given to the relationship established through e-commerce between the content provider and the buyer and, eventually, between both and a second provider, in order to verify what the treatment is appropriate legal framework for their accountability. Therefore, it is proposed the objective civil liability of the content providers according to the Consumer Protection Code, considering that, despite being a contractual relationship signed by a different communication vehicle, it is characterized as a consumer relationship, upon which all the peculiarities and prerogatives typical of this branch should fall.

Key-words: E-commerce. Content Providers. Consumer Relationship. Strict Responsibility. Consumer Protection Code.

\section{INTRODUÇÃO}

\footnotetext{
* ${ }^{1}$ Mestranda em Direito Processual pela Universidade Federal do Espírito Santo (UFES) e bolsista de mestrado pela Coordenação de Aperfeiçoamento de Pessoal de Nível Superior (CAPES). Pós-graduanda em Direito Público e em Direito Constitucional Aplicado. Graduada em Direito pela Faculdades Integradas de Vitória (FDV). http://lattes.cnpq.br/9480778211703946. ORCID: http://orcid.org/0000-0002-1238-9848. E-mail: lumavramos@gmail.com.

* ${ }^{2}$ Mestranda em Direito Processual pela Universidade Federal do Espírito Santo (UFES) e bolsista de mestrado pela Fundação de Amparo à Pesquisa do Espírito Santo (FAPES). Pós-Graduada em Direito Constitucional e Administrativo pela Escola Paulista de Direito (EPD). Graduada em Direito pela Universidade Vila Velha (UVV). http://lattes.cnpq.br/8481382166925968. ORCID: http://orcid.org/0000-0003-1830-0987. E-mail: andretto.isabella@gmail.com.
} 
Com o advento e consolidação do mundo capitalista, o ambiente tecnológico ganhou um espaço importante de atuação, de forma a, verdadeiramente, revolucionar o modo de vida dos cidadãos do novo século. Sem dúvida, a busca por agilidade e estabilidade do mundo contratual encontrou vazão no instrumento de comunicação mais flexível, porém mais sofisticado da Sociedade contemporânea: a internet.

Criada inicialmente para fins militares, a internet transformou-se em uma interface acessível, capaz de permitir que agentes, espacialmente distantes, pudessem interagir de forma imediata e com alta produção de conteúdo, por estarem ligados a uma rede global de comunicação. Nesse sentido, foi inevitável, diante de um rico cenário de interação interpessoal e de contratação em escala mundial, o surgimento de uma nova forma de comercialização de produtos e serviços, denominada e-commerce.

Nota-se que a nova faceta da comercialização é muito mais dinâmica e complexa do que a comercialização tradicional, uma vez que existem diversos sujeitos agindo para que uma contratação virtual seja realizada. Desse modo, não só aquele que comercializa o produto ou serviço na internet interage com o consumidor, mas também diversos outros atores digitais acabam relacionando-se com tais consumidores virtuais.

Isto ocorre porque, por traz de toda plataforma digital de comercialização existe, além dos provedores que mantém a estrutura virtual, aquele provedor que disponibiliza o produto ou serviço a ser consumido, assim como àqueles que possibilitam a disposição e acesso ao conteúdo da compra.

Assim, é de fundamental importância a análise do papel de todos os atores digitais responsáveis pela manutenção da rede de computadores, em especial dos provedores de conteúdo, uma vez que tais provedores atuam por meio da exposição, na internet, de produtos e serviços produzidos por outrem ou por ele mesmo.

Posto isso, faz-se necessário questionar: Qual tratamento jurídico adequado à responsabilização do provedor de conteúdo nas relações de $e$-commerce?

Em socorro a tal questão, propõe-se a responsabilização dos provedores de conteúdo nos moldes do Código de Defesa do Consumidor, por entender que, apesar de ser uma relação contratual firmada por um veículo de comunicação diferente, caracteriza-se como uma relação de consumo, sobre a qual deverão recair todas as peculiaridades e prerrogativas típicas deste ramo. 
O marco teórico deste trabalho foi construído, especialmente, com base nos estudos de Marcel Leonardi sobre os provedores, em suas diversificadas formas, da internet. Também foram importantes as lições trazidas por Sérgio Cavalieri Filho e Cláudia Lima Marques, no que diz respeito aos direitos do consumidor.

Ademais, adotou-se o método hipotético-dedutivo enquanto caminho para a discussão da hipótese de trabalho aqui defendida. Neste sentido, parte-se do pressuposto de que o Código de Defesa do Consumidor possui os regramentos necessários para a responsabilização civil dos provedores de conteúdo na internet.

Com o objetivo de enfrentar a questão, pesquisa voltar-se-á para o exame do tipo de relação formada no e-commerce entre o provedor de conteúdo e o comprador e, eventualmente, entre ambos e outros provedores, a fim de verificar qual o tratamento jurídico adequado para sua responsabilização.

\section{O CONTRATO ELETRÔNICO COMO NOVA FACETA DO INSTITUTO CONTRATUAL TRADICIONAL}

O instituto contratual pode ser compreendido como "um acordo de vontades, na conformidade da lei, e com finalidade de adquirir, resguardar, transferir, conservar, modificar ou extinguir direitos" (PEREIRA, 2012, p. 7-10). Para tanto "seu fundamento ético é a vontade humana, desde que atue na conformidade da ordem jurídica. Seu habitat é a ordem legal. Seu efeito a criação de direitos e de obrigações".

Como se nota, o contrato será, então, um negócio jurídico bilateral ou plurilateral, no qual as partes, munidas de sua autonomia da vontade, criam, modificam e extinguem direitos e obrigações. Contudo, o contrato não nasceu com a sua moldura atual, muito pelo contrário, sofreu transformações tão intensas, que torna possível afirmar a inexistência de uma evolução no conceito de contrato, mas uma verdadeira mudança em sua concepção.

$\mathrm{Na}$ Antiguidade, como assevera Bruna Lyra Duque (2007), o termo contrato não estava presente no Direito Romano, que tratava de forma geral as convenções, denominadas "stipulatio". Tal gênero comportava duas espécies: o “contractus" e o "pactum”, que, respectivamente, representavam um instrumento de acordo revestido de formalidade e outro sem forma alguma. 
As Codificações Modernas, por sua vez, devido à ressignificação dos valores sociais, e influenciadas pela corrente iluminista, romperam com os moldes contratuais advindos da fonte romana e buscaram, sobretudo, inovar o instituto, de forma a revesti-lo com a liberdade contratual e o informalismo.

Desta forma, o contrato deveria ser reflexo da real vontade humana, de modo a importar muito mais o que as partes desejavam, com a formulação de um acordo, do que a declaração das mesmas.

Neste sentido, segundo Roppo (2009, p. 297-301), nasce, no seio das Codificações Modernas, como representação dos ideais dos séculos XVII à XIX, a autonomia da vontade, expressão designada a exprimir a liberdade contratual do homem, sua igualdade formal e, sobretudo, a sua autonomia e capacidade de realizar acordos.

Diante do referido quadro social, o contrato era formulado individualmente, como um artefato produzido pelos contraentes em mesmo nível de capacidade de manifestação. Assim, seria possível a confecção de cláusula por cláusula do acordo de vontades, específico para determinada situação, fato que tornaria o contrato lei entre as partes, de forma a não ser cabível nenhuma intervenção em seus aspectos, seja estatal ou individual.

No entanto, com o advento do capitalismo, caracterizado pela alta circulação de bens, riquezas e intensas transações comerciais, o "imperativo é, de fato, o de garantir a celeridade das contratações, a segurança e a estabilidade das relações” (ROPPO, 2009, p. 298).

Em virtude disso, o contrato artesanal torna-se insatisfatório às necessidades do mundo contemporâneo, que clama pela substituição da importância atribuída "à vontade individual, às particularidades" por uma "teoria da declaração" (ROPPO, 2009, p. 298).

Tal teoria se caracteriza por priorizar o que o contraente externaliza como sua vontade e que os demais contratantes, conseguem receber como informação, de acordo com os padrões sociais estabelecidos e não necessariamente o que ele deseja em seu intimo. $\mathrm{O}$ Objetivo seria, então, destaca Roppo:

[...] de tutelar os interesses do destinatário da declaração, o qual tinha confiado no teor objetivo e socialmente perceptível desta: uma tutela de interesses individuais que - ao nível de todo o sistema - se converte justamente em garantia da segurança e da celeridade das trocas, da continuidade e estabilidade das relações de negócio. (ROPPO, 2009, p. 298)

Em outras palavras, como as relações contratuais contemporâneas se caracterizam pela agilidade da contratação e multiplicidades de vínculos entre vários contratantes, não é 
aceitável que os terceiros envolvidos, depositários de perspectivas, sujeitem-se aos desejos internalizados de uma das partes que, no momento da manifestação, não conseguiram externalizá-la.

Sendo assim, o foco da Teoria da Declaração é a vontade presente no contrato, sob as quais os terceiros envolvidos depositam suas expectativas, a partir da compreensão do seu conteúdo, o que demonstra a passagem de uma autonomia individual para uma autonomia privada.

Diante da alteração de uma perspectiva individualista do contrato, para uma maior padronização do mesmo, não houve a ruína do instituto, mas a sua intensa modificação, a fim de se adequar as necessidades contemporâneas.

Nascem, então, nesse cenário, os contratos de adesão (standard) e a contratação em massa, os quais, no ensinamento de Roppo (2009, p. 311-312), são usuais quando grandes empresas, movidas pela intensão de contratar com uma grande quantidade de sujeitos, fornecem, antecipadamente, para a aceitação mecanizada de qualquer contraente interessado, condições gerais, cláusulas, objetivos "aplicáveis, indistintamente, a todas as relações da série", e que, por isso, estão "sujeitas a uma mesma regulamentação".

Entretanto, é válido ressaltar que tal transformação veio acompanhada de uma série de ações estatais preocupadas em não tornar o contrato um meio particular abusivo das grandes corporações.

Por conseguinte, a intervenção estatal, por meio de normas jurídicas protetoras dos hipossuficientes e regradoras das relações contratuais, ou seja, por meio do dirigismo contratual, concedeu ao mundo privado uma função social, de forma a garantir que o contrato não seja um instrumento individual egoísta, mas que observe as necessidades sociais existentes.

Além da observância da função social e de outros princípios norteadores do contrato é preciso que este preencha certos requisitos para sua devida configuração.

Tais requisitos, organizados em três planos distintos, "servem para a análise minuciosa e científica do contrato, uma vez que permite a dissecação de seus elementos de constituição, os pressupostos de validade e os fatores que eventualmente inferem na sua eficácia jurídica" (GAGLIANO;PANPLONA, 2012, p.56).

Sobre este aspecto, convém iniciar pelo plano da existência dos negócios jurídicos, e, portanto, dos contratos. 
O plano da existência contém quatro requisitos a serem preenchidos, concomitantemente, para que o contrato possa existir, ou seja, ser configurado como tal.

O primeiro requisito é a manifestação da vontade que, segundo França (1996) consiste na conformidade de opiniões das partes para a configuração de uma relação jurídica, acerca de um objeto, seja de forma expressa ou tácita.

Ainda sobre os pressupostos de existência, devem encontrar-se, então presentes, os sujeitos que irão acordar sobre um objeto, de determinada forma.

Contudo, para validação de uma relação contratual não basta a simples manifestação de vontade, é preciso que essa manifestação se forme autonomamente, pois a presença de qualquer vício provocará a nulidade do acordo. Ademais, os sujeitos, responsáveis por tal manifestação, devem ser capazes.

É necessário ainda, segundo Gonçalves ( 2012, p. 37-38), que o objeto em questão seja lícito, ou seja, "aquele que não atenta contra a lei, moral ou os bons costumes"; possível física e juridicamente, no sentido de ser razoável a sua execução pelo homem médio e ser permitido pelo ordenamento jurídico. Acresça-se a isto, a ideia de que o objeto precisa ser determinado ou determinável, ou seja, aquele objeto completamente especificado quanto sua quantidade, espécie e qualidade ou aquele "suscetível de determinação no momento de execução", por só conter delimitado, inicialmente, a quantidade e a espécie.

Acresça-se a tais requisitos a forma, "que é o meio de relação da vontade" manifestada, a qual "é, em regra, livre. As partes podem celebrar o contrato por escrito, público ou particular, ou verbalmente, a não ser nos casos em que a lei, para dar maior segurança e seriedade ao negócio exija a forma escrita, pública ou particular" (GONÇALVES, 2012, p. 39).

Sendo assim, segundo os ensinamentos de Gonçalves (2012, p. 39-40), é possível afirmar que a forma consensual é tida pelo ordenamento brasileiro como uma constante, aplicada sempre que a lei não exigir a forma escrita, tida, então como uma exceção. Isto quer dizer que, em regra, as partes podem celebrar o contrato do modo que for mais conveniente ao negócio jurídico que celebram, pois somente se a lei exigir forma especial, no caso a forma escrita, é que as partes terão a sua autonomia privada mitigada pela exigência legal.

Por último, assevera Gagliano e Pamplona Filho (2012, p.45-60) que há o plano da eficácia, o qual diz respeito às consequências jurídicas alcançadas quando o contrato passa a gerar efeitos no mundo. 
É neste ambiente que os elementos incidentais encontraram oportunidade para atuarem, de forma a estabelecer condições, termos e encargos ao contrato.

Nota-se, portanto, que os requisitos atinentes ao instituto contratual são os mesmos dos negócios jurídicos em geral, ou seja, aqueles expressos no artigo 104 do Código Civil.

Entretanto leve-se ponderar que o contrato possui, além daqueles já relatados, um requisito próprio, identificado como consentimento recíproco e que se refere à necessidade de haver um acordo entre duas ou mais partes, revestidas da intenção de contratar, de negociar.

Sendo assim, desde que estejam configurados os aspectos legais exigidos, o indivíduo, munido de sua autonomia, pode valer-se do instituto contratual como meio de concretização de suas necessidades sociais, por meio da produção de acordos, capazes de produzir, transferir riquezas, além de criar, modificar e extinguir direitos e relações jurídicas.

Isso ocorre porque o instituto contratual é capaz de se adequar às necessidades de um mundo em intensas transformações, onde os interesses sociais estão sempre em mutação acelerada e globalizada, tornando-se assim um verdadeiro veículo para a promoção de relações sociais atualizadas e eficazes.

Esta capacidade de adaptação que permitiu a atual inserção do instituto contratual no mundo digital, por meio dos contratos eletrônicos, correspondendo, desde então, às expectativas de uma sociedade imersa em novas formas de comunicação, que incentivadas pelos Estados formaram massa digital, altamente produtiva e criativa.

Diante dessas novas formas de interação social, muito mais ágeis e complexas do que as tradicionais, o cenário contratual se renovou e "o Direito como um todo, independentemente da área de especialização, vê-se em face de fatos novos que o instam a manifestar-se, abrigando os que lhe são conformes, regulando os que não são" (BARBAGALO, 2001, p. 36-39).

Para tanto é preciso analisar a nova faceta do instituto contratual, denominado contrato eletrônico, caracterizado, principalmente, pela celeridade e massificação. Os contratos eletrônicos, segundo Bacelar (2003), podem ser definidos como "todo acordo de vontade, que modificam, criam ou extinguem direitos, celebrado por meio eletrônico, não sendo necessária à sua celebração a utilização de suporte físico para a exteriorização da declaração de vontade". 
Como se nota, os contratos eletrônicos não constituem um novo instituto jurídico, ao contrário, representam uma nova face do contrato tradicional, expresso pela plataforma digital.

Portanto, consistem em uma nova forma de "convergência de vontade com o intuito de produzir um efeito jurídico" (BARBAGALO, 2001, p. 1-4), que se diferenciam do contrato tradicional somente pelo meio de manifestação e concretização das vontades.

Sendo assim, os contratos eletrônicos devem apresentar, analogamente aos contratos tradicionais, os requisitos de existência, validade e eficácia dos negócios jurídicos, assim como os seus princípios norteadores, seguidos de algumas adequações.

Como ressalta Barbagalo (2001, p. 1-4), deve-se possuir uma especial atenção quanto ao requisito da capacidade das partes no tocante a contratação eletrônica, pois este meio permite a manifestação de vontade sem o contato físico e, portanto, abre possibilidades para vícios comuns, como a manifestação de um sujeito juridicamente incapaz, ou mesmo daqueles vícios característicos do mundo digital, como comandos puramente artificiais.

Decorre também deste distanciamento físico a necessidade de observância de alguns "elementos fundamentais da contratação eletrônica" (BACELAR, 2003), que a tornam tão segura quanto a contratação tradicional.

O primeiro elemento a ser respeitado pelos contraentes é a autenticidade, a qual deve ser relativa às partes, no que diz respeito a sua verdadeira identificação e à comunicação estabelecida entre os contratantes, para "assegurar ao agente a veracidade das informações trocadas" (BACELAR, 2003).

Outro ponto importante é a integridade das informações transmitidas, as quais são facilmente modificadas, devido ao uso do meio eletrônico, mas que para garantir a validade do contrato estabelecido, deve permanecer inalterada até a conclusão do acordo.

Por último, destaca Bacelar (2003) que a privacidade eletrônica e confidencialidade devem ser entendidos como objetivos a serem alcançados pelas partes na contratação eletrônica, visto que ao fechar um acordo é comum e necessária a troca de informações pessoais ou comerciais, muitas vezes sigilosas, uma vez que requerem o devido respeito e proteção pela outro contraente, o qual deve resguardá-las.

Decorrente do dever de proteger a informação prestada ao fechamento do negócio cabe ao contraente, que obteve tais informações, usá-las apenas para os fins permitidos, pois "o uso indevido de tais informações, mesmo por aqueles que detenham o acesso às 
informações em questão, considera-se quebra de confidencialidade, devendo ser apurada a responsabilidade civil e penal" (BACELAR, 2003).

Quanto às peculiaridades dos contratos eletrônicos, cumpre indagar se a formação deste contrato segue as regras atinentes aos contratos entre presentes e, portanto, instantâneos, ou entre ausentes, que implica na ocorrência de um lapso temporal.

Para analisar a questão é preciso esclarecer que o momento da formação do contrato eletrônico será, assim como no contrato tradicional, a ocasião em que há a convergência de interesses das partes, ou seja, quando existir a proposta e a respectiva aceitação, a partir da qual o contrato passa a gerar efeitos jurídicos.

No cenário eletrônico, a flexibilidade é uma característica inata e, por isso, é possível afirmar que existem situações de contratos firmados instantaneamente, ou seja, como se tivessem se concretizado entre presentes, e situações que pressupõe o lapso temporal.

No que tange às situações instantâneas, os contratos eletrônicos se manifestam pelas relações estabelecidas on-line, como compras em home pages, largamente utilizadas na contemporaneidade, e que seguem as regras atinentes aos acordos firmados entre presentes, no sentido de que o contrato se torna válido no momento em que houve a aceitação do oblato, geralmente manifestada em um clique.

As situações em que os contratos são firmados por mensagens eletrônicas, como $e$ mails ou mensagens de redes sociais, por sua vez, sujeitam-se à Teoria da Recepção de acordo com o Enunciado $\mathrm{n}^{\mathrm{o}} 173$ da Terceira Jornada de Direito Civil ${ }^{3}$, ou seja, considera-se o contrato válido a partir do momento em que o proponente recebe a aceitação.

Além dos elementos básicos a serem observados dentro de uma relação contratual eletrônica é de fundamental importância a sua sistematização, uma vez que a partir dessa organização é possível um maior aprofundamento e, consequente, especialização no assunto.

Ocorre que é possível adotar diversos critérios para a classificação dos contratos eletrônicos, levando em conta as mais variadas características que eles possuem.

Contudo, diante do objetivo almejado no presente trabalho, buscou-se uma classificação que leva em consideração os sujeitos da relação contratual, haja vista que a identificação desses sujeitos será essencial para a identificação dos sistemas legais que incidirão em cada tipo de relação eletrônica.

\footnotetext{
${ }^{3}$ Enunciado 173. "Art. 434: A formação dos contratos realizados entre pessoas ausentes, por meio eletrônico, completa-se com a recepção da aceitação pelo proponente."
} 
Nesse sentido, ensina Bacelar (2003) que os contratos eletrônicos podem ser classificados em quatro categorias, que se distinguem pelas "características das partes contratantes": "B2B (business to business)"; "B2C (business to consumer)"; "B2G (business to government)" e "C2C (consumer to consumer)".

A categoria B2B pode ser entendida como aquele contrato firmado entre duas ou mais partes que "exercem profissionalmente determinada atividade" (BACELAR, 2003), já os contratos B2C são aqueles realizados entre uma parte produtora de atividade e um consumidor.

O grupo dos contratos $\mathrm{B} 2 \mathrm{G}$ envolve o acordo de vontade entre uma parte produtora de atividade comercial e um "ente público" (BACELAR, 2003), e o C2C está relacionado aos contratos firmados diretamente entre consumidores.

É importante destacar, que a partir da classificação exposta é possível diferenciar o tipo de atuação estatal legiferante nas relações firmadas no meio eletrônico. Entretanto, para melhor compreender o assunto, faz-se necessário permear o meio em que a relação contratual é concebida e seus principais atores.

\section{OS PROVEDORES: ATORES NO E-COMMERCE}

Para que ocorra a formalização de uma operação comercial por meio eletrônico, mais precisamente, uma relação no e-commerce, não só o contratante e o contratado atuam para alcançar a comunhão de vontades, mas diversos outros atores digitais contribuem para a comercialização, na medida em que atuam para que todo o espaço contratual seja formado.

Sendo assim, é do trabalho conjunto de todos estes atores que nasce o ambiente cibernético propício à realização da contratação eletrônica.

Tais agentes digitais representam os provedores, os quais podem ser reunidos sob um gênero denominado como provedores de serviço de internet, entendido como aquela "pessoa física ou jurídica que fornece serviços relacionados ao funcionamento da internet, ou por meio dela" (LEONARDI, 2005).

Derivam deste gênero diversas espécies de provedores, cada qual com sua função específica na rede mundial de computadores: provedor de backbone, provedor de acesso, provedor de correio eletrônico, provedor de hospedagem, provedor de informação e provedor de conteúdo. 
Como o próprio nome intui, os provedores são agentes que irão prover determinado tipo de serviço para que seja possível a formação de uma plataforma digital capaz de viabilizar a contratação eletrônica. Para tanto, cada um deles assume determinado papel, ainda que em algumas situações um mesmo tipo de provedor exerça mais de uma função.

Portanto, a caracterização destes atores de acordo com a sua espécie é de fundamental importância para entender a sua função dentro de uma relação eletrônica e consequentemente para avaliar a sua responsabilidade.

Deste modo, ainda que existam situações em que o liame de diferenciação entre as espécies de provedor seja sensível, visto que muitas vezes um provedor exerce além de sua função principal outras atípicas a sua classificação, é preciso caracterizá-lo como pertencente a um ou mais grupos, para que assim seja possível regular a sua atuação e responsabilizá-lo corretamente.

Em virtude disso é preciso esclarecer que a primeira espécie de provedor é o provedor de backbone, o qual "oferece conectividade, vendendo acesso à sua infra-estrutura a outras empresas que, por sua vez, fazem a revenda do acesso ou hospedagem para usuários finais, ou que simplesmente utilizam a rede para fins institucionais internos" (LEONARDI, 2005).

Nota-se, por isso, que o provedor de backbone será aquela pessoa física ou jurídica que possui o aparato físico sobre o qual "trafega a quase totalidade dos dados transmitidos através da Internet, e é usualmente composto de múltiplo cabos de fibra ótica de alta velocidade" (LEONARDI, 2005), e que dificilmente terá contato com o contratante final de um produto ou serviço exposto no web site.

Noutra vertente, encontra-se também o provedor de acesso, aquela "pessoa jurídica fornecedora de serviços que possibilitem o acesso de seus consumidores à internet" (LEONARDI, 2005), e para isso, possuem uma conexão com um provedor de backbone ou possui ele mesmo uma estrutura física para o fornecimento da conexão.

Nas palavras de Adriano Vancin e Jefferson Matioli (2014, p. 177) o provedor de acesso basicamente, como seu próprio nome expressa, fornece acesso à rede mundial de computadores àqueles que utilizam os seus serviços, de modo que esses sujeitos possam assim acessar a Web.

Independente do modo que o provedor de acesso fornece a conexão, na essência, o contato entre ele o consumidor será relativo ao fornecimento do próprio serviço de acesso, o que significa que ele também não atua diretamente na relação do e-commerce firmada por 
meio das páginas da web, salvo situações em que ele mantém web site destinado a venda de seu serviço, momento no qual ele se encaixará em duas espécies de provedor, situação a ser trabalhada posteriormente.

Existe ainda o provedor de correio eletrônico, o qual "fornece ao usuário um nome e uma senha para uso exclusivo em um sistema informático que possibilita o envio e recebimento de mensagens", bem como provém "espaço limitado em disco rígido em um servidor remoto para o armazenamento de mensagens", as quais podem ser descarregadas pelo usuário ou mantidas na nuvem (LEONARDI, 2005).

Os exemplos de provedores de correio eletrônico são diversos, uma vez que o dia a dia dos grandes centros econômicos e acadêmicos exige dos cidadãos a manutenção de uma conta de e-mail com tais provedores. Posto isto, é possível citar como provedor de correio eletrônico o Gmail (Google), Hotmail (Microsoft), UOL Mail (Universo Online), dentre outros.

É preciso lembrar que, de modo semelhante com os outros provedores até então trabalhados, os provedores de correio eletrônico mantem relação com o consumidor final em relação a sua prestação de serviço, não atuando diretamente na compra e venda de produtos e serviço por páginas da $W e b$, malgrado muitas vezes traga anúncios e ofertas.

Ainda em relação aos provedores de serviço de internet, encontra-se como espécie o provedor de hospedagem, entendido como "a pessoa jurídica que fornece o serviço de armazenamento de dados em servidores próprios de acesso remoto, possibilitando o acesso de terceiros a esses dados, de acordo com a condições estabelecidas com o contratante do serviço" (LEONARDI, 2005).

Portanto, é aquele ator digital que fornece um espaço para que outro provedor possa utilizar de seu espaço para armazenar dados necessários à montagem de sua plataforma, como, por exemplo, um web site.

Neste sentido, explica Pedro Asensio (2001) que "o contrato de hospedagem é uma modalidade de contrato de (arrendamento de) serviços firmados por quem pretende explorar um web site através de um provedor de serviços de internet", pelo qual "o provedor proporciona ao cliente espaço no servidor em que se armazena a informação que constitui o conteúdo do web site, ao mesmo tempo que o conecta com a internet, facilitando o acesso de terceiros à informação ali contida". 
Por isto que as funções exercidas pelos provedores de hospedagem "são essenciais ao funcionamento do world wide web, e inerentes à existência de provedores de conteúdo, que necessariamente utilizam tais serviços para veicular informações na rede" (LEONARDI, 2005).

Entretanto, é relevante fixar que o este provedor não "exerce controle sobre o conteúdo armazenado em seus servidores" (LEONARDI, 2005), mas apenas disponibiliza o espaço de armazenamento para o provedor de conteúdo, que, por sua vez, terá total controle sobre as informações que ficam ou são excluídas da página. Logo, depreende-se que a relação que será firmada com o provedor de hospedagem terá como outro polo o provedor de conteúdo e não o contratante da página.

Por fim existem ainda os provedores de informação e os de conteúdo como as últimas espécies de provedores de serviço de internet.

O provedor de informação, segundo Leonardi Macel (2005) é "toda pessoa natural ou jurídica responsável pela criação das informações divulgadas através da internet”, ou seja, "é o efetivo autor da informação disponibilizada por meio do provedor de conteúdo". Já o provedor de conteúdo é entendido como "toda pessoa natural ou jurídica que disponibiliza na internet as informações criadas ou desenvolvidas pelos provedores de informação".

Por conseguinte, enquanto o provedor de informação é responsável, precipuamente, por criar informações, disponibilizar conteúdo de sua própria autoria, o provedor de conteúdo, é responsável, inicialmente, por veicular tais criações ou conteúdo.

Ocorre que muitas vezes o próprio provedor de conteúdo é quem produz as criações que serão veiculadas, de modo a provocar uma fusão entre o provedor de informação e de conteúdo em um só provedor, ensejando daí duas situações paradigma: a primeira quando o provedor de conteúdo é apenas o veículo para o conteúdo alheio e a segunda quando o provedor de conteúdo é veículo de conteúdo próprio.

Exatamente neste ponto que se situa o problema levantado pelo presente estudo, uma vez que independente do ângulo de análise da atuação do provedor de conteúdo verifica-se que ele interage diretamente com o contratante da página da web, ora como veículo de conteúdos, ora como produtor e veiculador de conteúdos.

Diante disto, surge a questão da possibilidade de responsabilização do provedor de conteúdo nas relações de e-commerce, a qual deve ser necessariamente analisada sobre os dois prismas levantados. 
Para isto é necessário que se verifique como se dá a relação do provedor de conteúdo com o contratante e como essa relação poderá ser classificada.

Então, em primeiro momento, tendo como paradigma a posição do provedor de conteúdo como mero veiculador de produtos e serviços dispostos pelos provedores de informação, tem-se a ideia inicial de que os provedores de conteúdo não teriam nenhum tipo de responsabilidade, já que o criador dos produtos e serviços é o provedor de informação, o qual deve assumir os riscos de seu negócio eletrônico.

Entretanto, ensina Leonardi Macel (2005) que o provedor de conteúdo, "na maioria dos casos, exerce o controle editorial prévio sobre as informações que divulga, escolhendo o teor do que será apresentado aos usuários antes de permitir o acesso ou disponibilizar estas informações".

Para facilitar o entendimento basta imaginar um web site que apesar de não vender produtos seus, mantém um página de compras com produtos de outros fornecedores, os quais são selecionados por ele por meio da realização de um contrato entre as empresas, ganhando, por meio desse plataforma de comercialização online, uma porcentagem em cima de cada venda.

Com a finalidade de aproximar ainda mais o leitor, pode ser citada como exemplo real a empresa Wine (INSTITUCIONAL, 2020), que mantêm um site de compras com os mais variados tipos de vinhos, dentro os quais nenhum é fabricado por tal empresa, que apenas mantém uma plataforma de venda dos produtos dos produtores de vinhos de todo o mundo, a partir da qual retira o lucro da empresa.

Nota-se, claramente, que os provedores de conteúdo, mesmo não sendo diretamente o fornecedor do produto, ou seja, aquele que fabrica o produto, ele tem o contato com o contratante diretamente, funcionando como se fosse um revendedor da mercadoria.

Ademais, em sua plataforma digital ele possui pleno controle de quais produtos ou serviços deseja veicular, bem como das informações que deseja transmitir para o contratante.

Desta forma, diante de algum erro que cause prejuízo para o contratante, seja em relação a erro de mercadoria, de qualidade, na negociação, questiona-se se o provedor de conteúdo estaria isento de qualquer responsabilidade, pelo simples fato de não ser ele o real fornecedor do produto ou serviço, ou pelo fato de que ele não tem controle sobre a fabricação dos mesmos. 
Defende-se neste estudo que é evidente a possibilidade de responsabilizar os provedores de conteúdo que atuam nas relações do $e$-commerce, tendo em vista a sua atuação direta com o comprador, bem como a possibilidade de controle sobre todas as compras realizadas e o aferimento de lucro.

Então, se quando o provedor de conteúdo atua como mero veículo é plausível a sua responsabilização frente aos danos provocados ao contratante, por muito mais razão haveria a possibilidade de responsabilização quando o provedor de conteúdo, além de veículo, é o próprio criador dos conteúdos.

Isso ocorre porque, além de ter contato direto com o contratante, possui controle total sobre os produtos e serviços mantidos na plataforma, sobre as informações que são transmitidas ao comprador, e ainda afere lucro sobre a atividade.

Deste modo, é necessário que em ambas as situações os provedores de conteúdo assumam os riscos da atividade que exercem. Mas, em quais moldes se daria tal responsabilização?

A resposta a tal questionamento implica na análise de qual seria a relação formada entre os provedores de conteúdo e os contratantes, de modo a verificar se existe uma relação de consumo ou um mero contrato civil.

\section{RELAÇÃO CONTRATUAL FORMADA PELO PROVEDOR DE CONTEÚdO NAS RELAÇÕES DO E-COMMERCE}

Com o intuito de averiguar qual a espécie de responsabilização cabível aos provedores de conteúdo faz-se necessária a classificação da relação firmada entre o provedor e o contratante em relação de consumo ou em relação civil.

Nesse ínterim, tendo como base os contornos acerca da relação de consumo expressos pelo Código de Defesa do Consumidor, bem como dos agentes que a compõe, faz-se necessário analisar se a relação estabelecida entre o provedor de conteúdo e o contratante é ou não relação consumerista.

Em primeiro momento é preciso identificar a posição do contratante em relação ao provedor de conteúdo. Tem-se que o contratante será aquela pessoa que por meio de uma interface digital irá adquirir produtos ou serviços que estão disponibilizados por meio da página da web, o website. 
Sendo assim, para que este contratante seja considerado fornecedor, segundo a Teoria Finalista Mitigada, adotado majoritariamente pela doutrina e jurisprudência contemporânea é preciso que ele assuma uma posição de vulnerabilidade em relação ao fornecedor, no caso o provedor de conteúdo.

É certo que no presente estudo não se pretende generalizar as situações de contratação pela internet. Entretanto, é inegável que a maioria das relações firmadas pela interface digital é feita entre o particular e aquele que fornece o serviço ou produto, sendo que o particular, simplesmente pelo fato de não conseguir ver, presencialmente, o produto ou serviço, não tem capacidade de analisar, com precisão, suas características e qualidades.

Além do mais, ensina Laginski (2014) que "os consumidores que adquirem produtos ou serviços envolvendo a utilização dos serviços dos provedores" estão sujeitos, quando acessam os meios de contratação de serviço ou produtos - página da web -, a uma imersão em um mundo de ofertas e propagandas, com "o objetivo de chamar a sua atenção para o consumo em geral", o que releva mais uma vez a vulnerabilidade no meio eletrônico.

Ciente desta posição de vulnerabilidade, decorrente do próprio meio de contratação, se torna possível afirmar que o contratante pode ser caracterizado como consumidor, na maioria dos casos, o que permite que esse contratante seja resguardado pelo CDC.

De outro lado, cabe a tarefa de examinar se o provedor de conteúdo poderá figurar como fornecedor, uma vez que a relação de consumo, para que assim seja caracterizada, necessita de um consumidor e de um fornecedor.

No que tange ao provedor de conteúdo ele poderá assumir duas posições dentro da contratação: a primeira quando ele veicula informações de outro provedor, qual seja, o provedor de informação, mas tendo controle sobre o conteúdo e as próprias informações veiculadas, bem como aferindo lucro dessa veiculação; a segundo quando ele além de veicular informações, ele mesmo as produz.

Quanto à primeira situação relatada, mesmo que o provedor de conteúdo não seja o produtor das informações que ele dispõe para acesso do consumidor, ele é responsável por todo um controle de conteúdo dessas informações, sendo responsável por escolher quais informações serão transmitidas e o modo que estas informações serão repassadas. Além disso, ainda afere lucros advindos dessa comercialização de produtos de outro provedor.

Pois bem, o artigo $3^{\circ}$ do Código de Defesa do Consumidor considera como fornecedor não só aquele que produz, cria produtos, mas também aquele que os distribui ou comercializa. 
Deste modo é incontestável que o provedor de conteúdo e o provedor de informação serão considerados fornecedores frente ao consumidor, mesmo que se revistam de uma feição digital.

Então, no tocante à segunda situação, em que o provedor de conteúdo, além de propagar o conteúdo é, integralmente, responsável por eles.

Com o intuito de aproximar o leitor de uma situação concreta, pode-se retomar o exemplo anteriormente discutido acerca da empresa Wine. Como já salientado a empresa Wine comercializa diversos tipos de vinhos que, malgrados não sejam produzidos por ela, são especialmente selecionados pela empresa, já que existe o objetivo de conquistar cada vez mais clientes.

Por meio desta comercialização e distribuição de vinhos a sociedade empresária afere lucro, sob forma de porcentagem a ser acrescida em cada venda.

Nota-se, portanto, que a empresa Wine, que trabalha exclusivamente por meio digital, é um típico fornecedor de produtos e de serviços, já que além de vender vinhos, disponibiliza por meio do Clube Wine (WINE INSTITUCIONAL, 2020), serviços de seleção de vinhos, de informações, e assinatura de revista para aqueles que se associarem ao Clube para ganharem descontos nas compras, o que revela uma típica remuneração indireta.

Evidente que se a empresa Wine pode ser caracterizada como fornecedora mesmo disponibilizando produtos de outras empresas, aquela empresa que é responsável por veicular conteúdo próprio também poderá ser qualificada como fornecedora.

À conta disto, nota-se que a relação firmada entre o provedor de conteúdo e o contratante online é uma relação de consumo, pois diante da configuração dos sujeitos da relação como consumidor e fornecedor mister a aplicação da lei especial, destinada a garantir a proteção da parte mais vulnerável.

Daí então, que a par da relação formada, faz-se necessário verificar qual a responsabilização do provedor de conteúdo nas relações do $e$-commerce.

\section{DA RESPONSABILIZAÇÃO DO PROVEDOR DE CONTEÚDO}

Como já exposto, o provedor de conteúdo, independente da forma de atuação - seja quando veicula conteúdo próprio ou conteúdo de outrem (provedor de informação) - pode ser 
enquadrado como fornecedor, ao passo que o contratante, que utiliza da página da web para adquirir produtos ou serviços, pode ser enquadrado como consumidor.

Diante de tal constatação evidente que o Código de Defesa do Consumidor deve atuar na referida relação contratual, caracterizada como de consumo, de modo a implicar a responsabilização objetiva do provedor de conteúdo.

Deste modo, diante da ocorrência de um fato do produto, ou seja, na ocorrência de um acidente de consumo, se o provedor de conteúdo for além do veiculador do produto (comerciante), o próprio fabricante, produtor, construtor ou importador do produto poderá ser demandado diretamente e solidariamente, salvo na hipótese de existência de alguma excludente do artigo $12, \S 3^{\circ}$, CDC.

Se, entretanto, for o veiculador dos produtos, caracterizando-se apenas como comerciante, sua responsabilização será subsidiária, nos moldes do artigo 13, CDC.

No caso de ocorrência de fato do serviço, o provedor de conteúdo poderá ser responsabilizado independente de figurar ou não apenas como comerciante de serviço de outrem, situação na qual ele apenas veicula conteúdo de outrem, pois todos que estão envolvidos na cadeia de produção e comercialização do serviço respondem solidariamente pelo fato do serviço, salvo no caso da existência de excludentes de responsabilidade.

Em ambos os casos é preciso que o consumidor observe o prazo prescricional de 5 anos estabelecido no artigo 27 do CDC.

De outro lado, na presença de um vício do produto, o provedor de conteúdo continua respondendo solidariamente, independente da forma que adota, pois todos aqueles que estão envolvidos na produção ou comercialização do produto são responsáveis.

Quanto às exceções presentes nos artigos $18, \S 5^{\circ}$ e $19, \S 2^{\circ}, \mathrm{CDC}$ relativa, respectivamente, ao fornecimento do produto in natura e ao produto que demanda pesagem ou medição por parte do fornecedor imediato, nota-se que o provedor de conteúdo poderá ser responsabilizado.

Isso ocorre porque ele é o responsável por veicular o conteúdo, ou seja, por comercializá-lo, de modo a ser, na maioria dos casos, aquele fornecedor imediato do produto in natura, bem como o responsável pela medição dos produtos.

Algo semelhante ocorre na presença de um vício no serviço, pois independente da forma assumida pelo provedor de conteúdo, simplesmente por ele estar inserido na cadeia de produção e comercialização do serviço ele poderá ser responsabilizado. 
Nestes últimos casos, referentes ao vício do produto ou serviço, o consumidor, ao invés de atender ao prazo prescricional, observará o prazo decadencial, presente no artigo 26 do CDC.

Em suma, uma vez caracterizada a relação estabelecida entre o provedor de conteúdo e o contratante é inevitável à incidência do Código de Defesa do Consumidor, que impõe, frente a um fato ou vício do produto ou serviço, a responsabilização civil de forma objetiva, ou seja, aquela que independe da comprovação da culpa em sentido amplo, importando, apenas para o consumidor, a comprovação do dano e do nexo de causalidade.

Tal situação garante, de forma mais intensa, a proteção do consumidor virtual, que munido da proteção concedida pelo CDC, poderá reaver seu direito de modo menos oneroso, já que a responsabilização será de modo objetivo.

\section{CONSIDERAÇÕES FINAIS}

Com o advento do mundo moderno, onde o desenvolvimento de tecnologia acompanha a crescente necessidade de agilidades nos moldes contratuais, surgiu uma nova faceta da contratação: a contratação digital.

Moldado nos mesmos princípios e instituto legais aplicáveis ao contrato tradicional, o contrato eletrônico exige todos os seus elementos característicos de uma contratação, quais sejam a configuração dos requisitos do artigo 104 do CC, o acompanhado do consentimento mútuo, acrescidos por princípios próprios como o da autenticidade, a integridade das informações, a privacidade e a confidencialidade.

Inseridos na contratação por meio eletrônico, o que hoje já é uma realidade para a maioria da população que possui acesso à internet, estão os diversos atores digitais que, a seu modo, colaboram para a promoção de um ambiente virtual propício a comercialização.

Neste cenário encontram-se: os provedores de backbone, os provedores de acesso, os provedores de correio eletrônico, os provedores de hospedagem, os provedores de informação e os provedores de conteúdo.

Cada provedor, a seu modo e de acordo com a sua função, possibilita a construção de um meio digital hábil a atender a demanda crescente de contratação ágil e em massa.

Entretanto, merece destaque o provedor de conteúdo, pois é ele o responsável pela veiculação e controle do conteúdo que é disponibilizado para aqueles que acessam a página da 
web. Conteúdo este que ora é de produção própria do provedor de conteúdo, ora é de produção de outro provedor, qual seja o de informação.

Este destaque se revela pelo fato de que o provedor de conteúdo é aquele que dispõe na web conteúdo seu ou de outrem para acesso dos usuários da rede. Além disto, é responsável pelo controle sobre este conteúdo veiculado, de modo a interagir diretamente com o contratante.

Por realizar papel fundamental na contratação eletrônica surge a questão da possibilidade ou não da responsabilização do provedor de conteúdo pelas relações firmadas entre ele e o contratante no e-commerce.

Ocorre que, diante da análise dos requisitos para a caracterização de uma relação de consumo, a qual perpassa pela própria análise dos seus sujeitos - fornecedor e consumidor depreende-se que o provedor de conteúdo e o contratante podem assumir as posições de fornecedor e consumidor, respectivamente, quando o contratante não comercializar os produtos ou serviços que o provedor dispõe na sua página da web.

Portanto, uma vez configurada a relação de consumo entre o provedor de conteúdo e o contratante, agora denominado, consumidor, inevitável será a aplicação do Código de Defesa do Consumidor, que diante da ocorrência de fato ou vício do produto ou do serviço, impõe a responsabilização civil do fornecedor de forma objetiva.

Isto significa que o fornecedor responderá independente de comprovação de culpa, de modo que o consumidor apenas deve provar a ocorrência do dano e do nexo de causalidade, para ver o seu direito de reparação efetivado.

Diante desta situação, depreende-se que o consumidor virtual está muito bem protegido perante a comercialização eletrônica, que, devida a distância que lhe é intrínseca, é um meio mais arriscado para o consumidor.

\section{REFERÊNCIAS BIBLIOGRÁFICAS}

ASENCIO, Pedro Alberto de Miguel. Derecho privado de internet. Madrid: Civitas, 2001.

BACELAR, Hugo Leonardo Duque. Direito e Internet: uma breve introdução aos contratos eletrônicos. Revista do Curso de Direito, Brasília, n. 2, dez. 2003.

BARBAGALO, Erica Brandini. Contratos Eletrônicos: contratos formados por meio de redes de computadores: peculiaridades jurídicas da formação do vínculo. Saraiva: São Paulo, 2001.

BRASIL. Código de Defesa do Consumidor. São Paulo: Saraiva, 2020. 
BRASIL. III Jornada de Direito Civil. Enunciado 173. Disponível em: <http://daleth.cjf.jus.br/revista/enunciados/iiijornada.pdf>. Acesso em: 26 abr. 2020.

DUQUE, Bruna Lyra. Análise Histórica do Direito das Obrigações. Disponível em: <https://jus.com.br/artigos/10030/analise-historica-do-direito-das-obrigacoes >. Acesso em: 26 abr. 2020.

FRANÇA. R. Limongi. Instituições de Direito Civil. São Paulo: Saraiva, 1996.

GAGlianO, Pablo Stolze; PAMPLONA FILHO, Rodolfo. Novo Curso de Direito Civil: Contratos: Teoria Geral. São Paulo: Saraiva, 2012.

GONÇALVES, Carlos Roberto. Direito Civil Brasileiro: Contratos e Atos Unilaterais. São Paulo: Saraiva, 2012.

GONZÁLEZ, Paloma Llaneza apud LEONARDI, Marcel. Responsabilidade Civil dos Provedores de Serviço de Internet. Disponível em: < http://leonardi.adv.br/wpcontent/uploads/2011/04/mlrcpsi.pdf>. Acesso em: 27 abr. 2020.

LAGINSKI, Valdirene. Responsabilização dos fornecedores no comércio eletrônico (ecommerce). Disponível em: <http://www.estig.ipbeja.pt/ ac_direito/responsabilidade_dos_fornecedores_no_comercio_ele tronico.pdf>. Acesso em: 27 abr. 2020.

LEONARDI, Marcel. Responsabilidade Civil dos Provedores de Serviço de Internet. Disponível em: < http://leonardi.adv.br/wp-content/uploads/2011/04/mlrcpsi.pdf>. Acesso em: 27 abr. 2020.

PEREIRA, Caio Mário da Silva. Instituições de Direito Civil: Contratos. Rio de Janeiro: Forense, 2012.

ROPPO, Enzo. O Contrato. Lisboa: Almedina, 2009.

VANCIN, Adriano Roberto e MATIOLI, Jefferson Luiz. Direito e Internet: Contrato Eletrônico e Responsabilidade Civil na Web. São Paulo: Lemos e Cruz, 2014.

WINE. INSTITUCIONAL. Disponível em: <https://www.wine.com.br/institucional/>. Acesso em: 27 abr. 2020.

WINE. Sobre o Clube Wine. Disponível em: <http://www.wine.com.br/wineinfo/clubew/>. Acesso em: 27 abr. 2020. 